\title{
Sabugo de milho e carvão ativado na produção de Lacase e Basidiomas de Pleurotus sp
}

\section{Corncob and active charcoal in the Laccase and Basidiome production of Pleurotus sp}

\author{
Magali Regina ${ }^{1 *}$; Luzia Doretto Paccola-Meirelles ${ }^{2}$; \\ Aneli de Melo Barbosa ${ }^{3}$; Ismael Rodrigues Amador; \\ Gisele Maria Andrade-Nobrega ${ }^{5}$; Diego Carlo Maschiare ${ }^{6}$
}

\section{Resumo}

O sabugo de milho é uma matéria prima lignocelulósica que pode ser uma opção viável para a produção de cogumelos comestíveis por fungos do gênero Pleurotus, considerando-se que existe uma enorme quantidade deste resíduo agrícola no Estado do Paraná e em todo o Brasil. Este trabalho avaliou três linhagens de Pleurotus sp., Pleurotus ostreatus (branco e CCB) e P. Eryngii (Salmão), como produtoras de lacase utilizando-se extrato líquido de sabugo de milho e em meio sólido à base de sabugo de milho, sem adicionar outras fontes de nutrientes. A linhagem de Pleurotus ostreatus (branco) produziu os maiores títulos de lacase no meio líquido $\left(1,2 \mathrm{U} \mathrm{L}^{-1}\right)$ e também no sólido $\left(\sim 2,8 \mathrm{U} \mathrm{kg}^{-1}\right)$ dentre as três linhagens avaliadas. A adição de carvão ativo aumentou a eficiência biológica $(30,3 \%)$ do $P$. eryngii (salmão) quando comparada com a ausência do mesmo (12,7 \%). Entretanto, a linhagem de P. ostreatus (branco) não apresentou diferença estatística entre os tratamentos, mostrando que a adição de carvão ativo ao meio sólido, para a produção de cogumelos, pode proporcionar um aumento na eficiência biológica, dependendo da linhagem utilizada.

Palavras-chave: Substratos, eficiência biológica, shimeji, enzimas

\begin{abstract}
Corn cob as a lignocellulosic feedstock could be a viable option for edible mushroom production by fungi of the genus Pleurotus considering that there are enormous amounts of this agricultural waste in the State of Parana, as well in the whole Brazil territory. This work evaluated three strains of Pleurotus sp., Pleurotus ostreatus (white and CCB), P. Eryngii (salmon), as laccase producers using liquid extract of corn cob, and solid medium based on corn cob without adding other nutritional sources. A strain of Pleurotus ostreatus (white) produced the highest titres of laccase in liquid medium $\left(1.2 \mathrm{U} \mathrm{L}^{-1}\right)$ and also on solid medium $\left(\sim 2.8 \mathrm{U} \mathrm{kg}^{-1}\right)$ among the three strains evaluated. The additon of active charcoal increased the biological efficency (30.3\%) of P. eryngii (salmon) when compared in its absence (12.7 $\%)$. However, the strain of $P$. ostreatus (white) did not present statistical difference among the treatments demonstrating that the addition of active charcoal to the solid medium for mushroom production can promote an increase in the biological efficiency depending upon the fungal strain used.
\end{abstract}

Key words: Substrate, biological efficiency, shimeji, enzymes

\footnotetext{
${ }^{1}$ Prof $^{\mathrm{a}}$ do Instituto Federal de Santa Catarina, Av. Expedicionários, s/nº, CEP: 89460970, Canoinhas, SC. E-mail: magaregina@, hotmail.com

${ }^{2}$ Prof $^{\mathrm{a}}$ do Dept ${ }^{\mathrm{o}}$ de Biologia Geral da Universidade Estadual de Londrina, UEL. Londrina, PR. C P 6001, CEP: 86.051-990. Londrina, PR. E-mail :paccola@uel.br

${ }^{3}$ Prof $^{\mathrm{a}}$ da Lakehead University, Biorefining Research Initiative, BRI, Oliver Road, Thunder Bay, ON, Canada. P7B 5E1. E-mail: anelibarbosa@gmail.com

${ }^{4}$ Pós-graduando do Dept ${ }^{\circ}$ de Química e Bioquímica, UEL, Londrina, PR. E-mail: ir_amador@hotmail.com

5 Prof. do Dept ${ }^{\mathrm{o}}$ de Biologia Geral, UEL. Londrina, PR. E-mail: giselenobrega@uel.br

${ }^{6}$ Discente do Curso de Agronomia, UEL. Londrina, PR. E-mail: diego_carlos17@hotmail.com

* Autor para correspondência
} 


\section{Introdução}

Diversos resíduos agrícolas lignocelulósicos existentes no Brasil têm sido utilizados no cultivo de cogumelos comestíveis, tais como palhas, gramíneas, serragens, cascas de frutas, sabugo de milho, bagaço de cana-de-açúcar, e outros de natureza orgânica (DONINI et al., 2005).

Fungos do gênero Pleurotus têm sido cultivados em uma ampla variedade de resíduos agroindustriais para avaliar a produção de cogumelos, os quais são mais consumidos rotineiramente no Japão e na China (MODA et al., 2005). Os cogumelos constituem fonte de proteína (YILMAZ et al., 2006) e de carboidratos, sendo estes últimos principalmente do tipo $\beta$-glucanos, os quais possuem propriedades antitumoral e imunomoduladora, visto que reforçam o sistema imunológico e protegem o organismo contra doenças (MIZUNO, 1999).

Vários resíduos lignocelulósicos têm sido pesquisados como substrato para o cultivo do Pleurotus ostreatoroseus, como serragem de madeira, farelo de cereais, ou resíduos resultantes do beneficiamento de arroz (BERNARDI et al., 2007). A produção de inóculo de $P$. pulmonarius também foi avaliada em cascas de amendoim, sabugo de milho e palha de arroz (OLIVEIRA et al., 2007), bem como a produção de basidiomas de $P$. sajorcaju em substratos à base de casca de café, palha e sabugo de milho, ou da palha do feijoeiro (DIAS et al., 2003). A palha de arroz, folhas de bananeira, capim-elefante também foram citados por Obodai, Cleland-Okine e Vowotor (2003) para o cultivo do P. ostreatus.

Fungos do gênero Pleurotus têm sido descritos como ligninolíticos, visto que são produtores de lacases, as quais são polifenol oxidases secretadas durante a formação dos primórdios e basidiomas na fermentação em fase sólida (SUGUIMOTO et al., 2001).

A adição de carvão ativo a resíduos lignocelulósicos durante o pré-tratamento, a quente, auxilia a solubilização de carboidratos, proteínas, compostos fenólicos, entre outros, proporciona a adsorção de certos fenóis e ou quinonas, que são compostos tóxicos para o metabolismo e consequente desenvolvimento dos fungos (ASSIS, TEIXEIRA, 1998), e aumenta a produção de basidiomas.

O Paraná é um dos estados brasileiros que se destaca na produção de milho; segundo o Instituto Brasileiro de Geografia e Estatística (IBGE, 2010), a produção de milho no Brasil, em 2010, foi de 53,1 milhões de toneladas, sendo que $20 \%$ destes correspondem à produção do Paraná, o que lhe conferiu o título de maior produtor nacional. Dada à disponibilidade de sabugo de milho tanto no Brasil como no estado do Paraná, este substrato constitui uma opção viável para agregar valor à produção de cogumelos comestíveis pelos fungos dos gêneros Pleurotus, Lentinula, entre outros (EIRA; MEIRELLES; PACCOLA-MEIRELLES, 2005; OLIVEIRA et al., 2007).

Portanto, neste trabalho foram avaliadas três linhagens de Pleurotus quanto à produção de lacase em extrato líquido obtido a partir de sabugo de milho, e também em meio sólido deste resíduo agroindustrial, sem adição de fonte nutricional. Também foi selecionada a melhor linhagem de Pleurotus avaliando-as quanto à eficiência biológica, em sabugo de milho tratado ou não com carvão ativado.

\section{Material e Métodos}

\section{Linhagens}

Foram avaliadas duas linhagens de Pleurotus ostreatus (branco e CCB), e uma linhagem de Pleurotus eryngii (salmão), pertencentes ao banco de microrganismos do Laboratório de Genética de Fungos do Departamento de Biologia Geral da Universidade Estadual de Londrina. As linhagens foram mantidas em meio sólido de BDA (Batata Dextrose Agar). 


\section{Meios de cultivo}

O substrato sólido utilizado tinha em sua composição $40 \%$ de material lignocelulósico, com umidade corrigida para $60 \%$. No total dos $40 \%$ de material lignocelulósico havia $79 \%$ de sabugo de milho, $20 \%$ de farelo de arroz e $1 \%$ de carbonato de cálcio $\left(\mathrm{CaCO}_{3}\right)$. Este foi o substrato utilizado para o preparo dos meios líquidos e sólidos de cultivo para a produção de lacase, como também o substrato da fermentação em fase sólida para a produção dos basidiomas, tendo sido alterado apenas quando o mesmo foi tratado com carvão ativado, substituindose $3 \%$ do sabugo de milho por carvão ativo, mantendo-se iguais as concentrações de farelo de arroz e $\mathrm{CaCO}_{3}$ previamente citadas.

\section{Produção de lacase em meio líquido de cultivo}

O meio líquido de cultivo foi preparado através do tratamento, a quente (10 min. em ebulição) de $200 \mathrm{~g}$ de substrato lignocelulósico em $500 \mathrm{~mL}$ de água destilada, o qual foi posteriormente filtrado em algodão hidrofílico e o volume final corrigido para $200 \mathrm{~mL}$. Os cultivos foram desenvolvidos em frascos de Erlenmeyer de $500 \mathrm{~mL}$, contendo os 200 $\mathrm{mL}$ do extrato líquido, após autoclavagem a $120^{\circ} \mathrm{C}$ (1 atm) por 30 minutos.

Cada frasco de cultivo foi inoculado com 10 discos de meio sólido de BDA $(1,5 \mathrm{~cm}$ de diâmetro), coberto com hifas de cada linhagem de Pleurotus (15 dias de cultivo). Após a inoculação, os frascos foram mantidos sob agitação a $180 \mathrm{rpm}$, em agitador orbital, no escuro, a $25^{\circ} \mathrm{C}$. Todos os cultivos foram desenvolvidos em triplicatas e os resultados constituem a média com os respectivos desvios-padrão.

As amostras para as análises das atividades de lacase foram obtidas aos 5, 7, 9, 12, 14, 16 e 19 dias após a inoculação. Foram coletadas duas amostras por repetição e transferidas para tubos de ensaio de 1,5 cm (tipo eppendorf). Cada amostra foi centrifugada por $5 \mathrm{~min}$ a $10.000 \mathrm{rpm}$ a $4^{\circ} \mathrm{C}$. Os respectivos sobrenadantes foram utilizados para as determinações enzimáticas.

\section{Produção de lacase em meio sólido}

Transferiu-se $10 \mathrm{~g}$ de substrato sólido para frascos de Erlenmeyer de $100 \mathrm{~mL}$. Após esterilização a $120{ }^{\circ} \mathrm{C}(1 \mathrm{~atm})$ por 20 minutos, cada frasco de Erlenmeyer recebeu 3 discos de meio sólido de BDA (1,5 cm de diâmetro) coberto com hifas de cada linhagem de Pleurotus, e foi incubado a $25^{\circ} \mathrm{C}$. A atividade lacásica foi determinada aos 8 , $11,13,18$ e 21 dias de cultivo. Todos os cultivos foram também desenvolvidos em triplicatas. O modelo experimental utilizado foi o inteiramente casualizado num esquema fatorial $4 \times 3$.

Para a obtenção do extrato enzimático, à cada frasco de cultivo foram adicionados $20 \mathrm{~mL}$ de água milli-Q esterilizada, em seguida, todos os frascos foram mantidos sob agitação a $50 \mathrm{rpm}$, por 1 hora. A suspensão obtida foi filtrada em algodão hidrofílico e o extrato recolhido foi utilizado para determinação da atividade de lacase. O substrato, após a extração, foi seco em estufa a $60^{\circ} \mathrm{C}$ até peso constante, para a determinação do peso seco. Os resultados foram avaliados estatisticamente pelo Teste $\mathrm{t}$ ao nível de $5 \%$ de significância.

\section{Determinação da atividade de lacase}

A atividade de lacase foi determinada espectrofotometricamente utilizando-se 2,6-dimetoxifenol (DMP- Fluka Chemika AG, Switzerland) como substrato, conforme descrito por Barbosa, Dekker e Hardy (1996), com modificações. Os ensaios foram incubados durante $5 \mathrm{~min}$ a $50^{\circ} \mathrm{C}$ em tampão McIlvaine $\mathrm{pH}$ 5,0 (57 mM) e o volume total da reação foi $1 \mathrm{~mL}$. As leituras foram desenvolvidas a $468 \mathrm{~nm}$ utilizando-se o $\xi=10000$ $\mathrm{M}^{-1} \mathrm{~cm}^{-1}$. A unidade de atividade de lacase (U) foi definida como $\mu \mathrm{mol}$ de DMP oxidado por minuto por litro (L) de extrato enzimático, ou por quilo $(\mathrm{Kg})$ de substrato seco. 
Comparação da produção de basidiomas em sabugo de milho tratado e não tratado com carvão ativado

Foram comparadas as linhagens de P. ostreatus (branco, e CCB) e a de $P$. eryngii (salmão).

Os substratos lignocelulósicos tratados e não tratados com carvão ativado (item 2.2) foram misturados em betoneira e acondicionados em sacos de polipropileno ( $800 \mathrm{~g}$ de substrato/saco). O material foi autoclavado a $120{ }^{\circ} \mathrm{C}(1 \mathrm{~atm})$ por 1 hora e 30 minutos. Grãos de trigo $(3 \mathrm{~g})$ cobertos por micélios com as respectivas linhagens de Pleurotus foram utilizados como inóculo. Os substratos inoculados foram mantidos em um galpão apropriado, com as laterais fechadas, contendo tela do tipo sombrite (80\%) para o desenvolvimento dos basidiomas, simulando a condição de muitos produtores de cogumelos. O chão foi mantido úmido, durante todo o período de produção, para uma umidade relativa do ar monitorada próximo de 75\%. Após a colonização dos substratos, os sacos receberam pequenos cortes para a formação dos basidiomas. A colheita foi desenvolvida quando os basidiomas atingiram $70 \%$ de abertura, até o término dos fluxos produtivos.

Os basidiomas colhidos foram pesados a fresco e o substrato, após o término da frutificação foi desidratado em estufa a $60{ }^{\circ} \mathrm{C}$, até peso constante, para determinação da eficiência biológica, conforme descrito a seguir:

Eficiência biológica $=$

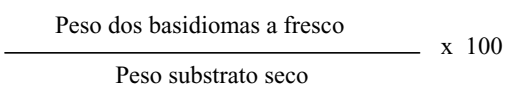

O experimento foi instalado com 10 repetições num delineamento experimental inteiramente casualizado e avaliado estatisticamente pelo Teste $\mathrm{t}$ ao nível de 5\% de significância.

\section{Resultados e Discussão}

Fungos do gênero Pleurotus têm sido descritos como ligninolíticos, sendo produtores de lacase (SUGUIMOTO et al., 2001). Portanto, foram comparadas as três linhagens cultivadas em meio líquido e em meio sólido quanto à produção de lacase, visto que são condições de fermentação diferentes, sem adição de fontes nutricionais, para avaliar a composição do extrato solúvel do sabugo de milho (fermentação submersa), bem como dos seus constituintes para o desenvolvimento das linhagens de Pleurotus (fermentação sólida), na síntese da lacase e assim selecionar a melhor linhagem.

\section{Produção de lacase por três linhagens de Pleurotus em meio líquido}

A Figura 1 mostra a produção de lacase extracelular de cada linhagem de Pleurotus avaliada. O Pleurotus ostreatus CCB iniciou a produção desta polifenol oxidase desde o $5^{\circ}$ dia mantendo a atividade até o $19^{\circ}$ dia de cultivo avaliado. O maior título de lacase $\left(0,36 \mathrm{U} \mathrm{L}^{-1}\right)$ foi atingido no $12^{\circ}$ dia de cultivo, enquanto que as outras linhagens avaliadas apresentaram os maiores títulos entre o $14^{\circ}$ dia pela linhagem $P$. ostreatus (branco) e $16^{\circ}$ dia pelo $P$. ostreatus (salmão), estatisticamente comprovado pelo teste de Scott Knott $(\mathrm{P} \leq 0,05)$. Entretanto, a linhagem de Pleurotus ostreatus (branco) foi a que se destacou quanto a produção de lacase $(1,2$ $\mathrm{U} \mathrm{L}^{-1}$ ) dentre as três linhagens avaliadas, embora a atividade tenha sido inferior às relatadas em outros trabalhos que também utilizaram sabugo de milho como substrato. Okamoto, Yanagi e Sakai (2000), por exemplo, descreveram a produção de $130 \mathrm{U} \mathrm{L}^{-1}$ de lacase por uma linhagem de $P$. ostreatus K16-2, no oitavo dia de cultivo. Mansur, Arias e Flärdh (2003) avaliaram a produção de lacase por outra linhagem de $P$. ostreatus e obtiveram máxima atividade no $5^{\circ}$ dia de cultivo ( $310 \mathrm{U} \mathrm{L}^{-1}$ ), também observaram um crescimento exponencial do $2^{\circ}$ ao $14^{\circ}$ dia de cultivo, determinado através da produção de biomassa, que foi acompanhado proporcionalmente pela produção de lacase. Entretanto, estes pesquisadores utilizaram um meio líquido completo, que continha extrato de levedura, o que favoreceu tanto a produção de biomassa como a produção de lacase. Portanto, 
não é possível comparar os resultados de produção de lacase obtidos no presente trabalho, no qual foi utilizado apenas o extrato do sabugo de milho, sem qualquer fonte adicional de carbono e ou nitrogênio, com os trabalhos descritos na literatura. Porém, foi possível constatar que as linhagens avaliadas produziram lacase e a linhagem $P$. ostreatus (branco) se destacou como produtora em um meio de cultivo não enriquecido com nutrientes, conforme consta dos objetivos do presente trabalho.

Figura 1. Perfil da produção de lacase por três linhagens de Pleurotus, em meio líquido de cultivo à base de extrato de sabugo de milho, mantidos sob agitação a $180 \mathrm{rpm}, 25^{\circ} \mathrm{C}$ durante 19 dias de cultivo.

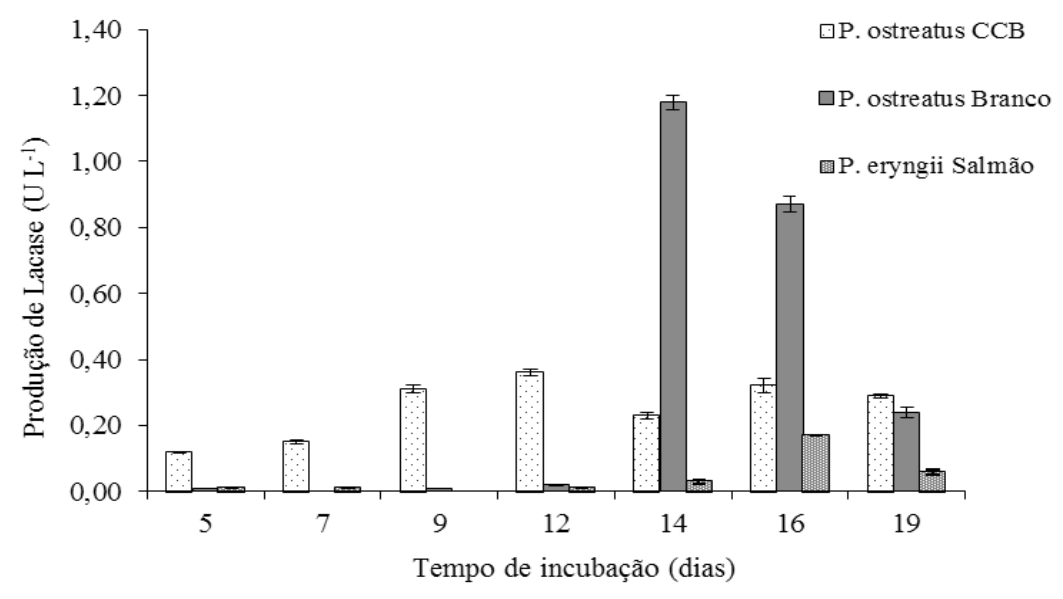

Produção de lacase por três linhagens de Pleurotus em meio sólido

O tempo de cultivo que proporcionou uma completa colonização do substrato pelas hifas dos fungos avaliados foi o escolhido para dar início na determinação de atividade de lacase produzida pelas linhagens avaliadas, visando simular o cultivo em sacos plásticos e correlacionar com as atividades de lacase com o crescimento do micélio antes da produção dos basidiomas. Portanto, não foi determinada a atividade de lacase nos tempos iniciais de cultivo, e sim a partir do $8^{\circ}$ até o $21^{\circ}$ dias (Figura 2.).

De forma geral, os maiores títulos de atividade de lacase produzidas pelas linhagens avaliadas foram obtidos entre o $8^{\circ}$ e $13^{\circ}$ dias, em concordância com os resultados descritos por Kamida et al. (2005), quando avaliaram a produção por duas linhagens de $P$. sajor-caju em bagaço de cana-de-açúcar e em efluentes têxteis, cujos picos de atividades foram obtidos no $9^{\circ}$ dia de cultivo. Cabe salientar novamente que a linhagem de $P$. ostreatus (branco) foi a que produziu maior título de atividade de lacase $\left(\sim 2,8 \mathrm{U} \mathrm{kg}^{-1}\right)$ no $8^{\circ}$ dia de cultivo. Todos os resultados foram analisados estatisticamente pelo Teste $\mathrm{t}$ ao nível de 5\% de significância.

Conforme descrito por Kerem, Friesem e Hadar (1992), uma linhagem de Pleurotus sp cultivado em substrato à base de resíduos da extração da fibra do algodão, mostrou um rápido aumento da produção de lacase do $2^{\circ}$ ao $6^{\circ}$ dias de cultivo, seguido de decréscimo nos dias subsequentes.

Os títulos de atividade de lacase decresceram, no decorrer do tempo, por todas as linhagens avaliadas, com exceção da linhagem CCB que teve um discreto aumento no $21^{\circ}$ dia. A linhagem de $P$. eryngii após o $13^{\circ}$ dia apresentou valores inexpressivos de atividade de lacase. Estes resultados indicam, provavelmente, que a atividade desta enzima pode estar associada ao crescimento micelial, visto que houve diminuição da mesma após o $18^{\circ}$ dia, quando já tinha ocorrido uma completa colonização do substrato. A atividade 
de lacase foi maior durante o crescimento vegetativo do $P$. cornucopiae, cultivado em palhada, e decaiu no período de formação do corpo de frutificação (KAVIYARASAN; NATARAJAN, 1997). O nível de atividade de lacase também declinou rapidamente durante a frutificação no cultivo de Lentinula edodes em substrato à base de serragem (OHGA et al., 2000; OHGA; ROYSE, 2001).
Durante algum tempo acreditou-se que a produção de lacase e de outras enzimas ligninolíticas estava relacionada à fase estacionária de crescimento (KIRK; FARRELL, 1987; HIGUCHI, 1990; REGINA et al., 2009). Entretanto, estudos posteriores demonstraram que deve haver outro mecanismo que rege a produção de lacase, durante a fase exponencial de crescimento, principalmente quando esta atividade parece estar estreitamente relacionada à produção de biomassa (MANSUR; ARIAS; FLÄRDH, 2003).

Figura 2. Perfil da produção de lacase por três linhagens de Pleurotus, em meio sólido de cultivo à base de sabugo de milho, durante 21 dias de cultivo.

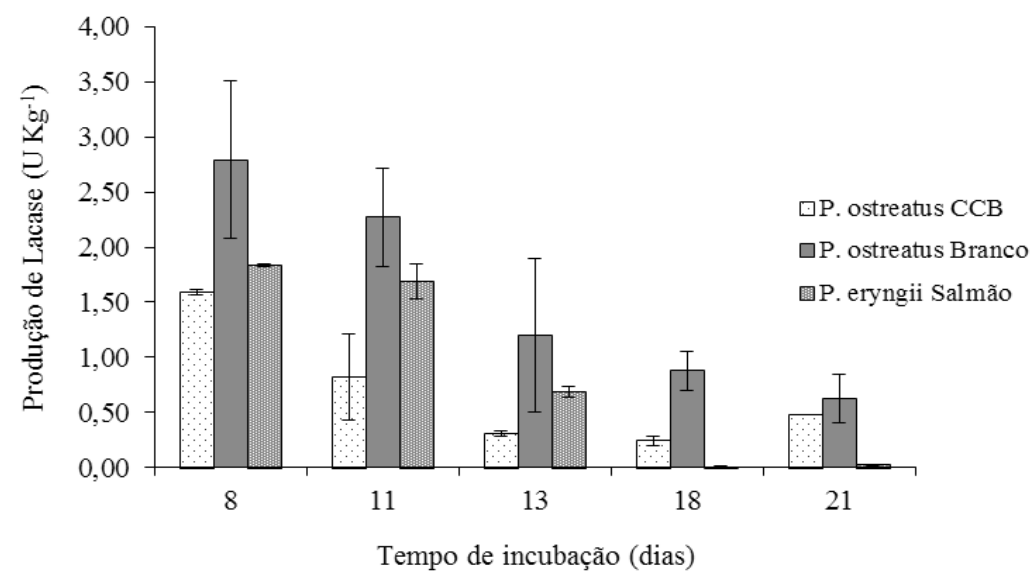

Eficiência Biológica das linhagens de Pleurotus com adição de carvão ativado

Embora as três linhagens avaliadas anteriormente quanto à produção de lacase tenham produzido a enzima, observou-se que a linhagem Pleurotus ostreatus (CCB) não frutificou em galpão, sem condições controladas, simulando às de muitos produtores de cogumelos (Figura 3).

A adição de carvão ativado foi importante para aumentar a eficiência biológica, conforme pode ser observado pelos resultados obtidos com a linhagem P. eryngii (salmão), cuja eficiência foi 30,29\% na presença de carvão e $12,67 \%$ na ausência. No entanto, para a linhagem $P$. ostreatus (branco) não houve diferença estatística entre os tratamentos. Portanto, parece que a adição de carvão pode ser eficiente dependendo da linhagem fúngica. 
Figura 3. Comparação da eficiência biológica entre $P$. ostreatus e $P$. eryngii na presença e ausência de carvão ativado.

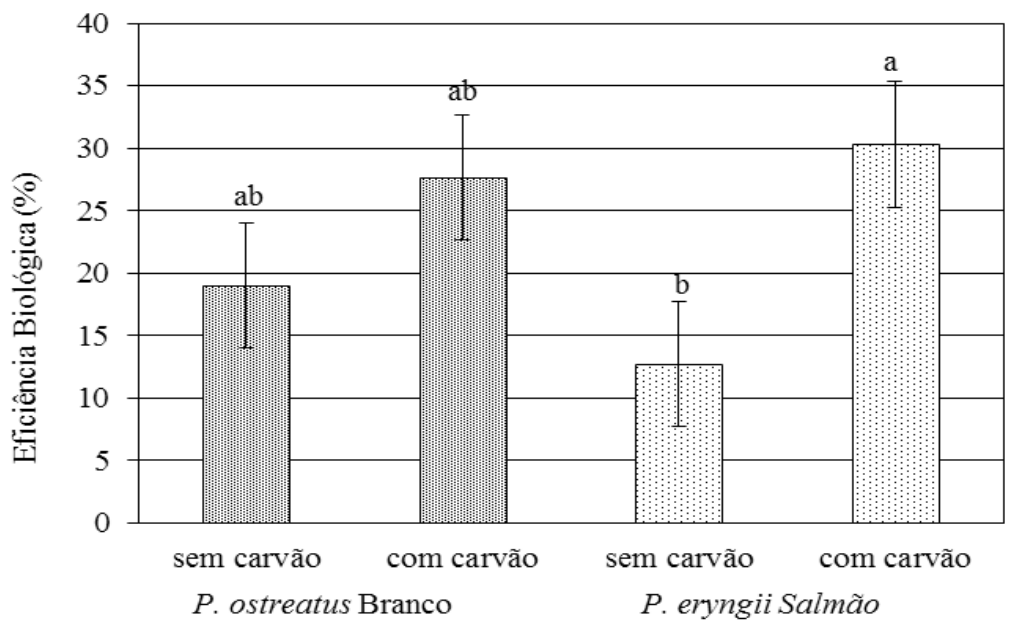

Resultados semelhantes foram descritos por Oliveira et al. (2007) quanto à eficiência biológica do P. pulmonarius, cultivado em substrato à base de sabugo de milho, a qual foi de aproximadamente $28 \%$.

Os valores de eficiência biológica obtidos por Eira, Meirelles e Paccola-Meirelles (2005) em substratos à base de sabugo de milho ou com mistura de serragem de eucalipto (1:1), não apresentaram diferença estatística entre 43,87 e $28,78 \%$, respectivamente, na produção de basidiomas de shiitake.

Os substratos devem proporcionar nutrientes e condições apropriadas para o crescimento micelial e produção de basidiomas; neste caso, o sabugo de milho, dentre as várias opções de resíduos agroindustriais deve ser considerado devido à sua disponibilidade no Paraná. Futuras pesquisas com adição de nutrientes ao sabugo de milho que favoreçam o crescimento fúngico e aumente a eficiência biológica, sem elevar o custo, devem ser incentivados visando estimular os produtores de cogumelos o uso deste substrato.

Vários autores têm avaliado o uso de carvão ativo na adsorção de compostos tóxicos presentes em hidrolisados lignocelulósicos (DOMINGUEZ;
GONG; TSAO, 1996; PARAJÓ; DOMINGUEZ; DOMINGUEZ, 1997; ALVES et al., 1998; MUSSATTO; ROBERTO, 2001). De acordo com McMillan (1994), os produtos derivados da lignina são os principais inibidores do crescimento microbiano em substratos lignocelulósicos.

Provavelmente, o carvão ativado tenha possibilitado a remoção de certos compostos prejudiciais ao crescimento e frutificação da linhagem de $P$. eryngii (salmão) o que auxiliou na obtenção da maior produtividade, o que não ocorreu com o P. ostreatus (branco) que pode ter sido mais resistente a estes compostos e, portanto, não apresentou diferença entre os tratamentos.

A grande maioria dos produtores de cogumelos produz de forma rústica e com pouca infra-estrutura estando, dessa forma, muito mais sujeitos às intervenções de clima, doenças e pragas, assim a contribuição de pesquisas direcionadas a estes produtores pode auxiliar na manutenção desta atividade para um grande número de famílias.

Estudos complementares ainda necessitam ser realizados verificando-se outros parâmetros que levem a um aumento da eficiência biológica utilizando-se o sabugo de milho como substrato. Pode-se constatar que o carvão ativado tem 
potencial de ser utilizado como complemento aos substratos preparados para produção de cogumelos, principalmente para melhorar a eficiência biológica em condições rústicas de cultivo para determinadas linhagens.

\section{Conclusão}

A ausência de fonte nutricional adicionada ao substrato de sabugo de milho conferiu uma baixa produção de lacase. A linhagem $P$. ostreatus (branco) apresentou os maiores índices de produção de lacase tanto em meio líquido quanto sólido. O carvão ativado, como componente em substratos de produção de cogumelos, pode auxiliar na melhoria da eficiência biológica de $P$. eryngii (salmão).

\section{Agradecimentos}

À Fundação Araucária e SETI-PR pela da bolsa de pesquisador visitante, modalidade recém-doutor, concedida.

\section{Referências}

ALVES, L. A.; FELIPE, M. G. A.; SILVA, J. B.; SILVA, S. S.; PRATA, A. M. R. Pre treatment of sugar cane bagasse hemicellulose hydrolysate for xylitol production by Candida guilliermondii. Applied Biochemistry and Biotechnology, New York, v. 70-72, p. 89-98, 1998.

ASSIS, T. F.; TEIXEIRA, S. L. Enraizamento de plantas lenhosas In: TORRES, A. C.; ALDAS, L. S.; BUSO, J. A. (Ed.). Cultura de tecidos e transformação genética de plantas. Brasília: Embrapa-SPI/ Embrapa-CNPH, 1998. p. $183-260$.

BARBOSA, A. M.; DEKKER, F. H.; HARDY, G. E. Veratryl alcohol as an inducer of laccase by an ascomycete, Botryosphaeria sp., when screened on the polymeric dye, poly R-478. Letters in Applied Microbiology, Oxford, v. 23, n. 2, p. 93-96, 1996.

BERNARDI, E.; DONINI, L. P.; MINOTTO, E.; NASCIMENTO, J. S. Utilização de diferentes substratos para a produção de inóculo de Pleurotus ostreatoroseus Sing. Revista Ciência Agronômica, Fortaleza, v. 38, n. 1, p. 84-89, 2007.
DIAS, E. S.; KOSHIKUMO E. M. S.; SCHWAN, R. F.; DA SILVA, R. Cultivo do cogumelo Pleurotus sajor-caju em diferentes resíduos agrícolas. Ciência e Agrotecnologia, Lavras, v. 27, n. 6, p. 1363-1369, 2003.

DOMINGUEZ, J. M.; GONG, C. S.; TSAO, G. T. Pretreatment of sugar cane bagasse hemicellulose hydrolysate for xylitol production by yeast. Applied Biochemistry and Biotechnology, New York, v. 57-58, n. 1, p. 49-56, 1996.

DONINI, L. P.; BERNARDI, E.; MINOTTO, E.; NASCIMENTO, J. S. Desenvolvimento in vitro de Pleurotus sp. sob a influência de diferentes substratos e dextrose. Arquivos do Instituto Biológico, São Paulo, v. 72, n. 3, p. 331-338, 2005.

EIRA, F. C.; MEIRELleS, W. F.; PACCOLAMEIRELLES, L. D. Shiitake production in corncob substrates. Revista Brasileira de Milho e Sorgo, Sete Lagoas, v. 4, n. 2, p. 141-148, 2005.

HIGUCHI, T. Lignin biochemistry: biosynthesis and biodegradation. Wood Science Technology, New York, v. 24, n. 1 p. 23-63, 1990.

INSTITUTO BRASILEIRO DE GEOGRAFIA E ESTATÍTICA - IBGE. Indicadores IBGE. Estatítica da produção agrícola maio 2010. 56 p. Disponível em: $<$ http://www.ibge.gov.br/home/estatistica/indicadores/ agropecuaria/lspa/default.shtm $>$. Acesso em: 17 jun. 2010.

KAMIDA, H. M.; DURRANT, L. R.; MONTEIRO, R. T. R.; ARMAS, E. D. Biodegradação de efluente têxtil por Pleurotus sajor-caju. Química Nova, São Paulo, v. 28, n. 4, p. 629-632, 2005.

KAVIYARASAN, V.; NATARAJAN, K. Changes in extracellular enzyme activities during growth and fruiting of Pleurotus cornucopiae var. citrinopileatus. In: RAI, R. D.; DHAR, B. L.; VERMA, R. N. (Ed.). Advances in mushroom biology and production. Solan: Mushromm Society of Indian, 1997. p. 309-320.

KEREM, Z.; FRIESEM, D.; HADAR, Y. Lignocellulose degradation during solid-state fermentation: Pleurotus ostreatus versus Phanerochaete chrysosporium. Applied and Environmental Microbiology, Washington, v. 58, n. 4, p. 1121-1127, 1992.

KIRK, K. T.; FARRELL, R. L. Enzymatic combustion: the microbial degradation of lignin. Annual Review Microbiology, Palo Alto, v. 41, n. 3, p. 465-505, 1987.

MANSUR, M.; ARIAS, M. E.; FLÄRDH, M. The whiterot fungus Pleurotus ostreatus secretes laccase isozymes with different substrate specificities. Mycologia, Stanford, v. 95, n. 6, p. 1013-1020, 2003. 
McMiLlAN, J. D. Conversion of hemicellulose hydrolyzates to ethanol. In: HIMMEL, M. E.; BAKER, J. O.; OVEREND, R. P. Enzymatic conversion of biomass for fuels production. Washington, 1994. cap. 21, p. 411437.

MIZUNO, T. The extraction and development of antitumor-active polysaccharides from medicinal mushrooms in Japan (review). International Journal of Medicinal Mushrooms, Redding, v. 1, n. 1, p. 9-29, 1999.

MODA, E. M.; SPOTO, M. H. F.; HORII, J.; ZOCHI, S. S. Uso de peróxido de hidrogênio e ácido cítrico na conservação de cogumelos Pleurotus sajor-caju in natura. Ciência e Tecnologia de Alimentos, Campinas, v. 25, n. 2, p. 291-296, 2005.

MUSSATTO, S. I.; ROBERTO, I. C. Hydrolysate detoxification with activated charcoal for xylitol production by Candida guilliermondii. Biotechnology Letters, New York, v. 23, n. 20, p. 1681-1684, 2001.

OBODAI, M.; CLELAND-OKINE, J.; VOWOTOR, K. A. Comparative study on the growth and yield of Pleurotus ostreatus mushroom on different lignocellulosic by-products. Journal of Industrial Microbiology \& Biotechnology, New York, v. 30, n. 3, p. 146-149, 2003.

OHGA, S.; CHO, N. S.; THURSTON, C. F.; WOOD, D. A. Transcriptional regulation of laccase and celullase genes in Lentinula edodes on a sawdust based substrate. Mycoscience, New York, v. 41, n. 1, p. 149-153, 2000.

OHGA, S.; ROYSE, D. J. Transcriptional regulation of lacase and celullase genes during growth and fruiting of Lentinula edodes on supplement sawdust. FEMS Microbiology Letters, Birmingham v. 210, n. 2, p. 111$115,2001$.
OKAMOTO, K.; YANAGI, S. O.; SAKAI, T. Purification and characterization of extracellular laccase from Pleurotus ostreatus. Mycoscience, New York, v. 41, n. 1, p. 7-13, 2000.

OLIVEIRA, M. A.; DONEGA, M. A.; PERALTA, R. M.; SOUZA, C. G. M. Produção de inóculo do cogumelo comestível Pleurotus pulmonarius (Fr.) Quélet. Ciência e Tecnologia de Alimentos, Campinas, v. 27, n. 1, p. 8487, 2007.

PARAJÓ, J. C.; DOMINGUEZ, H.; DOMINGUEZ, J. M. Improved xylitol production with Debaryomyces hansenii y-7426 from raw or detoxified wood hydrolysates. Enzyme and Microbial Technology, London, v. 21, n. 1, p. 18-24, 1997.

REGINA, M.; BROETTO, F.; GIOVANNOZZISERMANNI, G.; MARABOTINI, R.; PERANNI, C.; LiNDE, G. A.; COLAUTO, N. B.; PACCOLAMEIRELLES, L. D. Atividade de enzimas oxidativas do Lentinula edodes em substratos agroindustriais. Semina: Ciências Agrárias, Londrina, v. 30, n. 4, p. 881-888, 2009.

SUGUIMOTO, H. H.; BARBOSA, A. M.; DEKKER, R. F. H.; CASTRO-GOMEZ, R. J. H. Veratryl alcohol stimulates fruiting body formation in the oyster mushroom, Pleurotus ostreatus. FEMS Microbiology Letters, New York, v. 194, n. 2, p. 235-238, 2001.

YILMAZ， N.; SOLMAZ， M.; TÜRKEKUL， I.; ELMASTAS, M. Fatty acid composition in some wild edible mushrooms growing in the middle Black Sea region of Turkey. Food Chemistry, Davis, v. 99, n. 1, p. 168-174, 2006. 
